\title{
DERROTABILIDADE DAS NORMAS JURÍDICAS E A SUA APLICABILIDADE: O DIÁLOGO PRINCIPIOLÓGICO ENTRE O DIREITO CONTRATUAL CIVIL E O DIREITO CONTRATUAL ADMINISTRATIVO
}

\author{
DEFEASIBILITY OF LEGAL RULES AND ITS APLICATION: \\ THE PRINCIPLED DIALOGUE BETWEEN CIVL CONTRACT LAW \\ AND ADMINISTRATIVE CONTRACT LAW
}

Pablo Malheiros da Cunha Frota*

\begin{abstract}
RESUMO: Este artigo discorre sobre a teoria da derrotabilidade das normas jurídicas e o modo como ela pode ser utilizada pelo intérprete para que haja a incidência dos princípios contratuais civis também quando se analisa um contrato administrativo. Isso faz com que o intérprete valide o diálogo entre as formas de expressão do direito, bem como, em uma perspectiva crítica, repense a legitimidade e a validade de certos mitos principiológicos do direito administrativo, como a "supremacia do interesse público" que, para muitos, é o princípio vetor da disciplina jurídica administrativa. Pretende-se uma maior cooperação das partes no cumprimento contratual, independentemente de quem sejam os contratantes, a fim de que não haja mais súditos e reis e sim, cidadãos e Estado.
\end{abstract}

PALAVRAS-CHAVE: Derrotabilidade. Normas jurídicas. Diálogo. Princípios. Contratos. Civil. Administrativo.

ABSTRACT: This paper is about the "Defeasibility Theory" of the legal rules and the way it can be used by the one who interprets it, in order to have incidence of the civil contractual principles also when one analyses an public contract. This makes the interpreter validate a dialogue within the ways of expressing the Law, as well as, from a critical perspective, think again the legality and the validity of some logical principles of public law, such as the "public interest supremacy", which, for many, is the vector principle of the public law. The intention is a better cooperation from the parties regarding the contractual compliance, independent on who the parties are, so that there are vassals and kings no more, but citizens and the Nation.

KEYWORDS: Derogation. Juridical rules. Principles. Contracts. Civil. Public.

* Doutorando em direito na Universidade Federal do Paraná. Mestre em direito pela Faculdade Autônoma de Direito de São Paulo. Professor de Direito Civil da Universidade Católica de Brasília e de pós-graduação lato sensu. Associado do Caputo, Bastos e Fruet Advogados. E-mail: pablo.malheiros@yahoo.com 


\title{
1 O QUE SIGNIFICA DERROTABILIDADE DAS NORMAS JURÍDICAS?
}

\author{
"Sair da clausura dos saberes postos à reprodução e ir além \\ das restrições que o molde deforma. A produção das regras de \\ direito como ato de nascimento da vida e não certidão de \\ óbito a ser estampada no museu das praxes".
}

Luiz Edson Fachin

A sociedade contemporânea demanda novas hipóteses de investigação, a acolher outras formas de juridicidade e a recuperar a discursividade de valores como ética e justiça, por meio do entrelaçamento do direito com as demais ciências e com a sociedade. Esse caminho traz consigo dúvidas acerca de como as disciplinas jurídicas devem ser interpretadas no presente e no porvir, sem nunca desprezar o legado construído no pretérito.

A análise do direito atual não pode olvidar as características que cada tipo de Estado apresentou nos séculos XIX, XX e XXI: a) o Estado de Direito vigorou no século XIX e impôs uma concepção formalista fulcrada na supremacia constitucional, na tripartição dos poderes, no princípio da legalidade e na universalidade da jurisdição; b) o Estado Social, já no século XX, vinculou-se aos ditames do Estado de Direito, mas com uma atuação intervencionista ante a realidade socioeconômica (JUSTEN FILHO, 2009, p. 9-10), com o objetivo de atingir a justiça distributiva; c) o vigente Estado Constitucional - o Estado Democrático de Direito - açambarca as características estatais anteriores, porém qualificadas pelas dimensões do atual modelo estatal - juridicidade, democracia, socialidade e sustentabilidade ambiental -, pois o fim é a justiça socioambiental (SOARES, 2008, p. 189-216 e CANOTILHO, 1999).

O referido Estado Constitucional reforça a ideia de democracia hodierna - "espécie de interminável reorganização dos interesses individuais e coletivos" (JUSTEN FILHO, 2009 , p. 11). O exercício democrático por cada cidadão de seus direitos perpassa pelo consenso de todos acerca dos procedimentos, a fim de que possam participar, caso queiram, ativamente das decisões estatais sobre a criação, a instrumentalização e a implementação dos respectivos direitos. Essa participação dos cidadãos tem como fio condutor o processo comunicacional estatal com a sociedade, com os procedimentos devendo externar a vontade dos cidadãos, ${ }^{1}$ o que confere legitimidade ao citado processo comunicacional, de acordo com Habermas (2001, p. 164, 172 e 193).

O ordenamento jurídico não pode excluir a possibilidade de participação real e efetiva do cidadão na formação das normas jurídicas advindas do Estado, embora esta

1 Cidadãos são aqueles capazes de possuir direitos e deveres civis. Ressalta-se, porém, que diversos seres humanos são somente cidadãos formais, pois não conseguem exercer e efetivar a cartela de direitos conferidos pelo ordenamento jurídico, já que cumprem somente os deveres impostos, a faltar-lhes o aspecto material. A efetivação do princípio da cidadania - art. $1 .^{\circ}$, II, da CF/1988 - perpassa pela melhora das práticas institucionais, 
não tenha sido a realidade brasileira muitas vezes. Ressalte-se, contudo, que, no Brasil, o Estado não se comporta como deveria e o interesse estatal ao longo da história não tem refletido na maioria das vezes os interesses da sociedade, como se vê com a admissibilidade dos precatórios, das escorchantes cláusulas exorbitantes apostas nos contratos administrativos etc.

O intérprete não deve se afastar dos ditames constitucionais, porque a Constituição Federal de 1988, além delinear o Estado Democrático de Direito, concretizou direitos, deveres e importantes mudanças paradigmáticas no ordenamento jurídico brasileiro, como a força normativa dos princípios, a constitucionalização do direito (que "tem por fito submeter o direito positivo aos fundamentos de validade constitucionalmente estabelecidos") (LÔBO, 2009, p. 36), assim também o rompimento de diversas dicotomias, notadamente entre o direito público e o privado.

$\mathrm{O}$ atingimento dos objetivos constitucionais demanda que teoria e prática singrem juntas e não sejam antagônicas como atualmente se visualiza, tendo em vista a modificação da natureza das relações jurídicas atuais. Estas passaram de atomísticas, nas quais os interesses analisados se circunscreviam às partes, para moleculares, referentes às partes e à sociedade de forma direta ou imediata ou indireta e mediata, principalmente nas relações contratuais. Nesse passo, as teorias devem se conectar com a realidade e motivarem ações reais, porque a realidade é a concretude e fonte de criação das ideias, como se extrai das lições aportadas pelo materialismo histórico marxista (FACHIN, In: LIMA e BELLO, 2010, p. 143-154).

Torna-se necessário, portanto, verificar como é o manejamento teórico e prático das formas de expressão do Direito pelos intérpretes, a fim de que os objetivos constitucionais sejam exitosos. A mais conhecida forma de expressão do Direito é a norma jurídica, que não se confunde com as leis, pois estas podem conter inúmeras normas (p.ex. Código Civil), nem com os dispositivos de lei que a expressam (conjunto de palavras ou sinais linguísticos que exprimem as normas). Francisco Amaral conceitua a norma como "uma prescrição, um modelo de comportamento ou de organização que, por sua vez, representa valores ou fins a atingir, podendo ser considerada uma regra de motivação social indireta por sua influência no comportamento social” (AMARAL, 2008, p. 97-99).

Dessa maneira, a norma tem por características ser bilateral ou multilateral, porque pressupõe uma relação entre pessoas, como também ser coercitiva, possibilidade

constitucionais, jurídicas e dos instrumentos processuais, a fim de que os cidadãos participem da vida política do Estado e gozem dos direitos políticos, civis, econômicos, sociais e culturais que possuem, a concretizar a democracia participativa e a igualdade material - art. $3 .^{\circ}$, III, da CF/1988. Ver BARACHO, 1995, p. 1, 9, 10, 55, 56, 63 e 64; BARROSO e SOARES. In: BARROSO, 2006, p. 9-11. 
de coação (aplicação forçada da sanção - pena imposta ao infrator que não cumpriu o dever posto pela norma). A generalidade e a abstração não são características da norma, mas sim atributos desta (AMARAL, 2008, p. 100-103). Percebe-se, por conseguinte, que a norma jurídica abarca as regras (solução determinada acerca do comportamento dos sujeitos de direito) e os princípios (tradução genérica dos valores jurídicos e sociais sem atribuir um comportamento específico aos sujeitos de direito) (JUSTEN FILHO, 2009, p. 1).

O momento social e jurídico atual intensifica a importância dos princípios, por eles servirem à produção, à interpretação, à integração, à vinculação normativa, à direção, à aferição de existência, à validade, à eficácia e serem esteio da atividades existente na sociedade. Francisco Amaral traz também as funções dos princípios: metodológica, quando orientam o conhecimento, a interpretação e a aplicação das leis; ontológica, por serem fontes do direito; axiológica, por exprimirem valores fundamentais inspiradores e legitimadores do direito posto (segurança, justiça, bem comum etc.) (AMARAL, 2005, p. 24-31).

A resolução do conflito entre princípios em um caso concreto (p. ex. supremacia do interesse público versus os princípios sociais do contrato) demanda do intérprete uma solução que não parta de fórmulas preestabelecidas e sim, de uma construção argumentativa que utilize o caso concreto como parâmetro, as formas de expressão do direito (LIMONGI FRANÇA, 1988, p. 10-11) adequadas para aquela situação como fundamento, a fim de que haja a decisão justa para a hipótese em análise, independentemente se a decisão tomada é (ou não) contrária à lei - paradigma judicativo decisório (NEVES, 2003).

Contribuem para essa novel visão da interpretação e da realização do Direito as palavras de Nuno Coelho e de Francisco Amaral:

" $\mathrm{Na}$ investigação, portanto, do decidir concreto demonstra-se o prius metodológico do caso sobre a norma. $\mathrm{O}$ direito não é tido na conta de um objeto pré-constituído, mas como um problema de validade, como pensamento jurídico emergente sempre em/com situações humanas concretas que desafiam o homem a uma resposta de validade, que é uma resposta sobre si mesmo, uma resposta em que o homem se decide na convivência. A problematicidade do direito revela a feição radicalmente antidogmática desta perspectiva, o pensamento jurídico não se fundando sobre quaisquer sentidos dados antes da própria problematização, mas com a problematização mesma, isto é, com a realização concreta do direito e ao ensejo da sua vivência. $\mathrm{O}$ ponto de partida antidogmático captura o direito como pergunta, que o espírito perpetra no seu transcender constitutivo". (COELHO, 2008, p. 16-38)

“cujas principais coordenadas são o caso, como prius problemático, e os princípios jurídicos como prius fundamentante, a caracterizar o pensamento jurídico como razão prática e como pensamento judicativo-decisório (...) a convocar os juristas, advogados e magistrados, para a tarefa, hercúlea sem dúvida, como requer Dworkin, mas irrecusável para um direito civil que se quer vivente". (AMARAL, 2006, p. 3-24) 
O paradigma judicativo-decisório não elimina ou mitiga a segurança jurídica, mas ao contrário, a reforça como segurança NO DIREITO E NÃO DO DIREITO (BARROSO, 2006, p. 601-610). A solução de um caso concreto estará no direito haurido da sociedade e concatenado com os princípios e os valores constantes do ordenamento jurídico. A lei é tão somente uma das formas de expressão do Direito para resolver as questões jurídicas de uma sociedade complexa, pluralista, massificada e tecnológica.

A metodologia de realização do Direito acima exposta necessita ainda do amparo de um modelo interpretativo capaz de estabelecer uma releitura conceitual das formulações dogmáticas dos institutos jurídicos e inclusiva das hipóteses fáticas não positivadas, somente alcançável por meio da utilização de uma linguagem filosófica que implique o intérprete relativamente ao objeto analisado. A formulação teórica de Robert Brandom, por ele intitulada inferencialismo (BRANDOM, 2002), uma vez transportada para as ciências sociais aplicadas poderia ser adequada ao contexto das ciências jurídicas, refazendo as matrizes da discursividade racional que permeia a interpretação do Direito, afastando-se definitivamente daquela de natureza lógico-dedutiva para se ocupar com as repercussões de sua atuação no meio social.

O paradigma judicativo decisório, o inferencialismo e a percepção crítica (COELHO, 2003), constitucionalizada e prospectiva propostas reaproximam o Direito dos valores éticos que o inspiram e buscam densificar os conceitos e os institutos jurídicos a partir dos imperativos da realidade socioambiental e emanados das variadas formas de expressão do Direito.

Essas perspectivas fáticas, sociais, econômicas, jurídicas e filosóficas podem ser enriquecidas com uma refinada metodologia que una as categorias retrocitadas denominada de derrotabilidade - teoria surgida em 1980 "no Departamento de Ciência da Computação da Universidade de Columbia Britânica, Vancouver, Canadá, com R. Reiter, e na Universidade de Stanford, Califórnia, Estados Unidos, com John McCarthy (...)." Certo é que o mote inicial era a criação de programas de computador com sistemas lógicos de linguagem que se aproximassem do raciocínio humano, de acordo com Serbena e Cella. (SERBENA e CELLA, Prefácio VASCONCELOS, 2010, p. 8)

Esse estudo gerou a criação de sistemas lógicos não monotônicos, ou seja, segundo doutrina, "de um conjunto inicial de premissas, deduzimos uma certa conclusão, mas, uma vez adicionada uma outra premissa ao mesmo conjunto inicial, as conclusões já deduzidas não continuam valendo necessariamente. Dependendo da premissa adicionada, ela pode 'derrotar' a conclusão original e proporcionar uma nova conclusão. Essa é a forma de pensar que os seres humanos utilizam na maioria das vezes em que é necessário raciocinar" $\left(" \mathrm{p} \rightarrow \mathrm{r}\right.$ e ( $\left.\left.\mathrm{p}^{\wedge} \mathrm{q}\right) \rightarrow-\mathrm{r} "\right)$, como aludem Serbena e Cella. Na lógica monotônica ou silogística, todavia, não se alteram as conclusões deduzidas das premissas iniciais mesmo que se 
adicionem novas informações $\left(\mathrm{p}\right.$ implica $\left.q^{\prime \prime}(\mathrm{p} \rightarrow \mathrm{q}) \rightarrow\left[\left(\mathrm{p}^{\wedge} \mathrm{r}\right) \rightarrow \mathrm{q}\right]\right)$ (SERBENA e CELLA, Prefácio VASCONCELOS, 2010, p. 66-69). Aduz Andreoni Vasconcelos (2010, p. 47): "Entre "perdas e ganhos" de cada padrão lógico, a não monotonicidade se destaca porque autoriza a representação dos embates argumentativos de forma mais realista, dentro daquilo que geralmente ocorre quando se pretende aplicar uma previsão do direito positivo em um cenário litigioso".

Em 1990, cultores da lógica começaram a utilizar as lógicas não monotônicas para trabalhar o raciocínio jurídico (HACK, 2002), já que a todo momento os operadores do direito modificam o seu entendimento a cada nova informação apreendida. Explicitar ferramentas para a construção de uma resposta séria, fundamentada e correta é o que objetiva a teoria da derrotabilidade das normas jurídicas, elegante metodologia para o pós-positivismo (SERBENA e CELLA, Prefácio VASCONCELOS, 2010, p. 7-9). Quem confere as respostas são os legisladores e os juízes e a lógica auxilia na definição de consequências jurídicas ou a clarificação do caso concreto (VASCONCELOS, 2010, p. 32-33).

Não existem, porém, muitas referências no Brasil sobre a mencionada teoria, ao contrário do que acontece na literatura estrangeira (p. ex. NEIL MACCORMICK, ROBERT ALEXY, EUGENIO BULYGIN, CARLOS ALCHOURRON, HENRY PRAKKEN, JAAP HAGE, MANUEL ATIENZA e ALEXANDER PECZENICK), que analisa a derrotabilidade no âmbito da argumentação jurídica (BAYÓN e RODRÍGUEZ, 2003).

Hart (na obra The ascription of responsibility and Rights) foi o idealizador da derrotabilidade jurídica, não sendo a derrotabilidade uma nova categoria jurídica, mas um fenômeno empírico verificável, "pelo qual certas categorias jurídicas (como incidência, aplicação, antinomias, lógica deôntica, entre outras) receberão um colorido diferente", como afirma a doutrina. Andreoni sustenta que a relação regra/exceção não é nova no direito, mas Hart confere nova abordagem sobre o tema ao afirmar que a presença de uma exceção pode afastar ou fazer não incidir os efeitos jurídicos da norma de conteúdo e estrutura perfeitos, sendo a derrotabilidade uma situação excepcional (VASCONCELOS, 2010, p. 53-55).

A derrotabilidade (defeasibility) das normas jurídicas se refere à interpretação do Direito a partir das diferentes realidades fáticas e jurídicas, passando ao largo das questões de revogação ou derrogação, uma vez que não se pode desconsiderar sem a devida fundamentação o direito positivo. Andreoni sustenta que é "uma teoria que se propõe a representar seriamente a não-aplicação da mensagem literal do direito positivo, ainda que presentes os requisitos necessários e suficientes para aplicação", pois "os valores da segurança jurídica e do princípio democrático estão presentes de forma explícita ou implícita, em todo o raciocínio desenvolvido" (VASCONCELOS, 2010, p. 15-16). Afasta-se, portanto, a possibilidade de uma única interpretação, a valorizar o 
caso concreto e o intérprete - jungindo interpretação e aplicação - já que a norma jurídica deriva do resultado da interpretação do Direito. ${ }^{2}$

O termo derrotabilidade é plurívoco, mas conserva um núcleo comum conceitual que afasta, derrota ou não se aplica a norma jurídica se um fato, uma interpretação ou circunstância for com ela incompatível, como se extrai das situações exemplificativas de hipóteses impeditivas, modificativas ou extintivas do direito alegado pela parte no bojo de uma relação processual, em que será aplicada uma norma excepcional em detrimento da norma geral (VASCONCELOS, 2010, p. 57-58).

Diante disso, a prescrição posta no art. 927 do Código Civil ("Aquele que, por ato ilícito (arts. 186 e 187), causar dano a outrem fica obrigado a repará-lo") poderá ser afastada por meio da teoria da derrotabilidade que tutela essas situações de incidência da hipótese fática sem a natural consequência prevista no texto legal. A genitora que ministrou remédio para a sua filha (v.g. talidomida) e lhe causou um dano não irá repará-lo, já que esta responsabilidade é do Estado (que autorizou a comercialização) e dos laboratórios (que fabricaram o remédio e não o testaram adequadamente e geraram danos para várias pessoas que o ingeriram), diluindo-se a responsabilidade da mãe, em homenagem as premissas postas pelo direito de danos. A derrotabilidade torna possível novas interpretações advindas do cotejo da regra com um princípio ou com uma circunstância especial (MACCORMICK, 2008, p. 310 e ss).

Andreoni alude que a derrotabilidade "pode ser entendida como uma nova categoria jurídica que, apesar de não ser incluída no estudo do constitucionalismo moderno, constitui pressuposto de qualquer teoria que defenda a excepcionalização de regras jurídicas (como a teoria dos princípios). Para a derrotabilidade, além disso, ela aparece como desdobramento dos deveres prima facie e com eles impõe a revisão de categorias jurídicas, como a juridicização e a incidência", embora se defenda que a derrotabilidade não é uma nova categoria jurídica, mas um fenômeno empírico verificável, conforme aludido por Hart. Frise-se que todas as normas podem ser derrotadas, haja vista que dependerá das circunstâncias do caso concreto, por ser a derrotabilidade uma presunção relativa (VASCONCELOS, 2010, p. 63-64, 78).

Por tudo isso, aduzem Serbena e Cella (Prefácio VASCONCELOS, 2010, p. 9) a relevância de se estudar a derrotabilidade:

"A derrotabilidade, enquanto propriedade formal de certas regras de inferência, cumpre um importante papel. Com ela, pensamos, os princípios jurídicos podem adentrar à teoria do Direito pela porta da frente, sem se refugiar em antigos jusnaturalismos há muito superados pela crítica positivista.

2 Giorgio Agamben, no mesmo sentido, destaca o motivo pelo qual se começou a pensar assim a interpretação do Direito: “(...) a aplicação de uma norma não está de modo algum contida nela e nem pode ser dela deduzida, pois, de outro modo, não haveria necessidade de se criar o imponente edifício do direito processual." (AGAMBEN, 2004, p. 62-63) 
Outro ponto que gostaríamos de enfatizar é que a derrotabilidade retira o tapete que encobre a maneira usual de raciocinar dos juristas. Ela faz ver que as regras de inferência utilizadas pelo raciocínio jurídico são, em sua maioria, não monotônicas. Alguns criticam a derrotabilidade afirmando que ela traz insegurança jurídica. A crítica é infundada, pois, geralmente, quem a formula não é consciente de que, ao raciocinar, a utiliza na maioria dos casos condicionais derrotáveis, porém não admite expressamente essa realidade, ou por artifício retórico ou por falta de rigor científico, ou mesmo por desconhecimento".

Desse modo, a teoria da derrotabilidade das normas jurídicas representa a possibilidade de tratamento de casos excepcionais, dentro de uma norma geral e abstrata aplicável prima facie a todas as situações normais ou típicas, entendimento aplicável aos enunciados, julgados pacíficos e súmulas vinculantes dos Tribunais.

É possível, portanto, o intérprete afastar a literalidade de uma norma jurídica administrativa sem ofender os valores e princípios constitucionais e infraconstitucionais? Tentar-se-á demonstrar no tópico seguinte que a derrotabilidade auxilia muito a análise do direito posto, a partir da análise de um julgado do Tribunal de Justiça do Distrito Federal e dos Territórios (TJDFT).

\section{A DERROTABILIDADE DAS NORMAS JURÍDICAS APLICADA PARA FUNDAMENTAR O DIÁLOGO EXISTENTE ENTRE OS PRINCÍPIOS CONTRATUAIS DO DIREITO CIVIL E DO DIREITO ADMINISTRATIVO - DA SUJEIÇÃO À COOPERAÇÃ̃o}

“O cidadão não é um súdito, um inferior, um servo do Estado. Os governantes e os governados encontram-se em posição de igualdade, ainda que haja competência dos primeiros de tomarem decisões vinculantes para todos. A competência decisória atribuída aos agentes estatais não se funda na posição de supremacia ou superioridade deles em face dos governados".

Marçal Justen Filho

Canotilho afirma, com absoluta razão, que as decisões recentes de vários Tribunais Constitucionais não se apoiam em "grandes teorias" e não abordam "problemas metódicos-metodológicos de interpretação - concretização das normas constitucionais, a existir um "positivismo jurisprudencial" - "precedentismo metodológico fechado "aplicando-se as normas aos casos levados aos Tribunais" (CANOTILHO, 2006, p. 427$439,428)$, entendimento extensível para qualquer Tribunal pátrio.

$\mathrm{O}$ método jurídico confere coerência e consistência racional às respostas construídas para os problemas jurídicos, não podendo a jurisprudência se tornar um decisionismo desprovido de métodos, como destaca Andreoni Vasconcelos (2010, p. 27): 
"A derrotabilidade encontra-se inserida neste conceito de método e, como tal, foi desenvolvida pela doutrina para promover a racionalização do "momento jurídico" em que muitos diriam residir o decisionismo, o subjetivismo, ou mesmo, a desmetodização. O raciocínio empreendido em todo o trabalho esta imbuído da vontade de "racionalizar, explicar e dominar" o ato de aplicação do direito positivo, sobretudo quando o fenômeno da derrotabilidade entra em jogo".

Verificar-se-á, com fulcro nas premissas jurídicas, sociais e filosóficas, se as conclusões do acórdão abaixo são derrotáveis (ou não) e se é possível haver um diálogo principiológico contratual entre o direito civil e o direito administrativo para que haja cooperação e não sujeição nas relações contratuais administrativas.

O TJDFT decidiu:

ADMINISTRATIVO - PROCESSUAL CIVIL - APELAÇÃO CÍVEL - AÇÃO DE OBRIGAÇÃO DE FAZER - CONTRATO DE PRESTAÇÃO DE SERVIÇOS - CONTRATANTE - PESSOA JURÍDICA DE DIREITO PRIVADO - SERVIÇO SOCIAL AUTÔNOMO - NORMAS DE DIREITO PRIVADO DENÚNCIA UNILATERAL POR QUALQUER DAS PARTES CONTRATANTES - PREVISÃO CONTRATUAL - LUCROS CESSANTES E/OU DANOS MATERIAIS - IMPERTINÊNCIA.

1. Os serviços sociais autônomos regem-se pelas normas do Direito Privado, com as adaptações expressas nas leis administrativas de sua instituição e organização.

2. Previamente realizado o processo licitatório, a empresa apelante sagrou-se vencedora no certame, celebrando com o SENAI um contrato de prestação de serviços. O contratante notificou regularmente a empresa contratada com a finalidade de denunciar o contrato, nos termos de cláusula contratual livremente pactuada entre as partes litigantes, não restando afastada a presunção de legalidade e legitimidade do ato administrativo que ensejou a rescisão contratual, dado a que nenhum particular, ao contratar com a Administração, adquire direito à imutabilidade do contrato ou à sua execução integral.

3. Na exegese dos atos praticados pelo SENAI, tem-se que a comunicação unilateral de rompimento do contrato de prestação de serviços em comento foi emanada do exercício discricionário do Administrador, a quem legitimamente, se confere a opção da conveniência e oportunidade da continuidade contratual.

4. Igualmente, o pleito de indenização por lucros cessantes e/ou danos materiais, em razão da rescisão unilateral do contrato, não procede. Além de haver cláusula contratual prevendo a denúncia unilateral do contrato a qualquer tempo, sem cabimento de indenização às partes, há o direito da contratada ao recebimento das faturas correspondentes aos serviços já realizados. Descurou a empresa apelante de comprovar os prejuízos que assevera haver experimentado, eis que não realizada qualquer prova neste sentido.

5. Apelação conhecida e não provida. Sentença mantida. ${ }^{3}$

Debate-se no caso qual é a natureza jurídica pública ou privada da ré (SERVIÇO NACIONAL DE APRENDIZAGEM INDUSTRIAL - DEPARTAMENTO NACIONAL - SENAIDN) e a possibilidade de resilição contratual de prestação de serviços pactuado entre as

3 TJDFT - APC 20070110369489. 3ª T. Cível. Rel. Des. Humberto Adjuto Ulhôa. DJ de 03/06/2008. Revista da Faculdade de Direito - UFPR, Curitiba, n.52, p.81-99, 2010. 
partes, pois o Senai é por contribuições parafiscais (CF, art. 240). Deliberou-se que o Senai é uma entidade paraestatal (pessoa de cooperação governamental) - pessoa jurídica "de direito privado no exercício de atividades que produzem algum benefício para grupos sociais ou categorias profissionais". O Senai, portanto, não faz parte da Administração Pública direta ou indireta "mesmo empregando recursos públicos provenientes de contribuições parafiscais." ${ }_{4}$

Diante disso, sustenta o acórdão que:

“A Constituição Federal dirige o princípio da obrigatoriedade da licitação somente à administração direta e indireta, consoante artigo 22, inciso XXVII. Ademais, o artigo 37 também é dirigido somente aos entes integrantes da Administração Pública, os quais devem observar os princípios ali expostos na realização de suas atividades. (...) Evidente que a origem da verba não o descaracteriza como dinheiro público, mas não impõe ao ente paraestatal a obrigatoriedade de observar os princípios e normas direcionadas exclusivamente à Administração Pública, eis que não é permitido ampliar o âmbito de incidência previsto pelo legislador constituinte."

A teoria da derrotabilidade incide sobre a dicção do acórdão de restrição de aplicabilidade do art. 37 da CF/88 àqueles que não integram a Administração Pública, já que a atuação do particular e do Estado não pode se distanciar dos ditames constitucionais, assim como deve privilegiar a autoridade do argumento ao argumento de autoridade. Dessa maneira, tanto o particular quanto o Estado devem atuar de forma cooperativa, porque normalmente o segundo comete inúmeras injustiças em detrimento dos direitos dos cidadãos, com esteio em supostas "prerrogativas" (rectius privilégios) conferidos por leis e por decisões judiciais à Administração Pública (FROTA In: HIRONAKA e TARTUCE, 2007, p. 547-580, 549), ainda com base no instrumental teórico do século XIX e nas "soluções opacas e desconstituídas de transparência, tais como "discricionariedade administrativa", "conveniência e oportunidade" e "interesse público" (JUSTEN FILHO, 2009, p. 15).

$\mathrm{O}$ direito administrativo, portanto, deve ser uma disciplina jurídica reguladora da atividade administrativa exercida pelo Estado ou por particulares, com a chancela do primeiro, a fim de organizar as estruturas sociais, bem como possibilitar o exercício dos direitos individuais e coletivos que cada pessoa detém. $O$ regime administrativo restringe a autonomia dos sujeitos de direito com o intuito de "reduzir o risco de não serem atendidas certas necessidades ou de sacrifício dos valores fundamentais vigentes", segundo Marçal Justen Filho (2009, p. 1).

A conceituação de interesse público e a sua propalada supremacia sobre o direito civil devem ser questionadas, pois, como defende Menelick de Carvalho Neto, ${ }^{5}$ não existe

4 STJ - $1^{\text {a }}$ Seção; CC 41246/SC; Relator Ministro Castro Meira; DJ 27/09/2004.

5 NETO, Menelick de Carvalho. Os direitos fundamentais e a crise institucional do Distrito Federal. Palestra proferida na Faculdade Processus do Distrito Federal em 22 de fevereiro de 2010. 
um só tipo de direito que seja individual e não tenha repercussão coletiva e nenhum direito coletivo que não atinja a esfera íntima do cidadão, a tornar somente didática uma possível nova dicotomia individual e coletivo, como propugnada Gregório Assagra (2008, p. 603). Revisam-se, destarte, os pilares do Direito administrativo - supremacia do interesse público sobre o interesse privado, legalidade administrativa como vinculação positiva à lei, intangibilidade do mérito administrativo, Poder Executivo unitário - a fim de adequá-los à tessitura constitucional (BINENBOJM In: NETO e SARMENTO, 2007, p. 743-780, p. 748-750). ${ }^{\circ}$

Desses quatro modelos advêm os princípios do direito administrativo postos expressamente (ou não) no art. 37 da Constituição Federal de 1988: legalidade, impessoalidade, moralidade, publicidade, eficiência, finalidade pública, presunção de legitimidade, controle judicial dos atos administrativos, devido processo legal, obrigatoriedade do desempenho da atividade administrativa, continuidade dos serviços públicos, igualdade, responsabilidade do estado, motivação (implícito), legitimidade da despesa pública, economicidade, razoabilidade, autotutela (ESPÍNDOLA In: LEITE, 2003, p.254-293, p. 278-279).

Esse olhar diferenciado acerca do direito administrativo atinge o direito civil, que também deve servir a vida (CARVALHO, 1981, v.1). Isso porque a civilística contemporânea deve se afastar do individualismo, da neutralidade, do tecnicismo e do saber virtual, aproximando-se do tempo em que é aplicado e da historicidade concreta, a partir de uma postura crítica, cujos vetores são a teoria e o caso concreto, sem desconsiderar o que está posto. Isso porque o direito civil incide sobre a existência, o desenvolvimento e o fim dos sujeitos de direito tutelando situações patrimoniais e existenciais que repercutem não somente sujeito individualmente tratado, mas em toda a sociedade.

Adota-se a divisão principiológica realizada por Castanheira Neves (2003, p. 108) para a classificação dos princípios civilísticos: (i) positivos (expressos pelo direito posto); (ii) transpositivos (transcendentais e estruturantes de diversas formas de expressão do Direito); (iii) suprapositivos (expressam valores fundamentais do Direito) para abordar os princípios civis. $O$ direito civil sofre a influência constitucional, cujos princípios positivos abarcam os constitucionais fundamentais $\left(\mathrm{CF} / 88\right.$, arts. $1^{\circ}, 3^{\circ}$ e $\left.5^{\circ}\right)$, que se sobrepõem sobre qualquer norma e os institucionais, que abrangem os diversos institutos jurídicos, por exemplo, os princípios do direito das famílias, dos contratos, das propriedades etc. Os transpositivos são no direito civil os princípios da eticidade, da operabilidade e o da socialidade e os princípios suprapositivos são o da justiça, o da liberdade, o da segurança, o da igualdade e o da dignidade da pessoa humana (AMARAL, 2008, p. 65). Em síntese, os princípios regedores do direito civil são: o da dignidade da pessoa humana, o da

6 Veja as reflexões de Marçal Justen Filho (2009, p. 44-164). 
solidariedade, o da igualdade, o da liberdade, o da autonomia privada, o da boa-fé, o da função social (LÔBO, 2005, p. 67-102) e o da função ambiental.

Está na hora de se construir um direito administrativo e um direito civil democrático, cooperativo e que realmente reflita os interesses sociais e não somente os estatais ou dos particulares, na perspectiva utilitarista como se tem visto, a afastar a restrição posta no acórdão acerca do art. 37 da $\mathrm{CF} / 88$, cuja aplicação deve ser mediada para também ser efetiva no âmbito privado, embora topograficamente $\mathrm{o}$ artigo constitucional esteja inserido na parte da Administração Pública. O entendimento sufragado no acórdão é o senso comum da maioria dos intérpretes, porém foi derrotado pelas circunstâncias fáticas e jurídicas pelas quais passam o Direito e a sociedade, a fortalecer a teoria da derrotabilidade das normas jurídicas, até porque os princípios lá encetados podem corroborar para uma melhor tutela das relações entre os particulares.

Em outro ponto o julgado aduz:

"Desta forma, entendo que a celebração de contrato pelo Senai com observância das normas de direito privado é perfeitamente válida, podendo incluir cláusulas que manifestem o arbítrio das partes, como a 9.5, debatida nos autos, que permite denunciar o contrato a qualquer tempo sem qualquer indenização, desde que com prévia comunicação de trinta dias.

Aludida prerrogativa também estava à disposição da autora, que desde o início das tratativas tinha conhecimento desta disposição contratual, conforme cópia da minuta do contrato que estava anexa ao convite (fls. 40), não tendo impugnado nenhuma norma do ajuste".

Segundo o acórdão, as partes não se submetem à principiologia encartada no art. $37 \mathrm{da} \mathrm{CF} / 88$ e sim às normas civis, o que autoriza a resilição unilateral do contrato sem indenização, desde que haja a comunicação com trinta dias de antecedência, utilizou o art. 78 da Lei n. ${ }^{\circ}$ 8.666/93 para autorizar a resilição unilateral. Frise-se, porém, que a contratação foi precedida de licitação, que o contrato era por adesão às condições gerais e não pactuado livremente como apôs o julgado, utilizando-se das prerrogativas da Administração Pública para manter a resilição unilateral sem qualquer indenização por falta de prova.

Certo é que a própria resilição unilateral sem as cautelas devidas já comprovam o dano, pois o contrato tinha uma expectativa de execução protraída no tempo e que não se realizou. No mínimo, portanto, tinha o particular direito a alguma reparação por um prazo determinado, como coloca o art. 473, parágrafo único do Código Civil. A autora da demanda pode ter investido consideravelmente para executar o contrato, que era por adesão às condiç̃̃es gerais, fator desconsiderado pelo julgado que não observou os arts. 423 e 424 do Código Civil e 54 do Código de Defesa do Consumidor.

A teoria da derrotabilidade novamente incide no julgado para afastar as suas conclusões, em razão de circunstâncias fáticas, jurídicas e sociais, e gerando outra solução para o caso em comento. 
Atualmente as fontes de poder são plurais e circulam em cadeia (FOUCAULT, 1996, p. 182), a autorizar a relativização dos poderes e princípios atinentes à Administração Pública ao contratar bens e serviços de particulares, ante a possibilidade de diálogo entre as formas de expressão do direito, assim como com as demais ciências e com a sociedade, sempre a partir do caso concreto, pois a interpretação não mais se divide em integração e aplicação e se torna uma operação única integral para a concreção do Direito e solução de um caso concreto (AMARAL, 2009, p. 12, 15, 16, 19, 20 e 22), a jungir o texto no contexto.

Utiliza-se a teoria crítica para interpretar o direito civil e o direito administrativo, pois ela conjuga conhecimento e metodologia didático-pedagógica, teoria e prática, bem como busca uma hermenêutica construtiva, fulcrada na axiologia constitucional. A teoria crítica altera o modo de exame dos institutos jurídicos, podendo, inclusive, alterar suas definições e seus elementos de existência, requisitos de validade e efeitos produzidos (FACHIN, 2008, p. X, 18-21).

Essa travessia do passado para o presente com foco no porvir detém meios para ser realizada pelo intérprete: a) criticar as classificações de base diante do contexto jurídico e delas extrair o que de adequado ao momento atual elas podem conferir; b) demonstrar a ilogicidade dos papéis das dicotomias, que harmonizam - confrontando-se direito objetivo/direito subjetivo - e que separam, segundo Fachin, "privando do público o lado privado das coisas e das pessoas"; c) compreender que o Direito Civil é parte do molde teórico de raso alcance prático para a partir daí tentar torná-lo mais efetivo na práxis da vida; d) perceber que o Direito Civil não se resume nas normas civis, estudandose as fontes dessa disciplina incluindo quem os Códigos Civis excluem; e) conferir a importância devida aos princípios - fundamento do Direito Civil - reconhecendo a autonomia, a igualdade, a pessoa concreta, os direitos da personalidade, a responsabilidade na liberdade contratual em detrimento somente da propriedade, as famílias e as relações de seus membros e não só da família entidade, bem como, de acordo com Fachin, "fotografar a legitimidade da herança e direito de testar na concessão que também outorga personalidade jurídica aos entes coletivos" (FACHIN, 2003, p. 7-9).

A possibilidade de ajustamento de interesses decorre de uma percepção cooperativa entre a atividade estatal e a atividade dos particulares, mormente em uma relação contratual (PERLINGIERI, 2002, p. 212), em que os sujeitos de direito não são simplesmente servos dos interesses da Pública Administração. A cooperação é elemento preponderante nas relações entre particulares, entre Estado e particulares e entre Estado e Estado, a teor do pensamento de Rafael Peteffi da Silva: "Mesmo as ações do direito positivo estatal já estão sendo caracterizadas menos pelo seu caráter soberano e mais pela cooperação entre as partes atingidas, pois o Estado necessita da cooperação dos 
grupos sociais para implementar suas políticas" (PETEFFI DA SILVA In: PEREIRA e SILVA, LEWIS, SANTOS, MARQUES, 2006, p. 137-174, p. 168).

Nessa linha, aos tradicionais elementos obrigacionais (partes, vínculo e prestação) (LÔBO, 2005, p. 65-68) acrescem-se o interesse do credor, do devedor e da sociedade, porque as relações obrigacionais de qualquer espécie importam ao todo e a todos, já que tem por conteúdo centros de interesses juridicamente relevantes e protegidos pelos princípios da dignidade da pessoa humana, da igualdade material e formal, da cidadania formal e material e da solidariedade constitucional (TEPEDINO, BARBOZA, MORAES, 2007, p. 208, 209 e 494), entre outros.

A análise crítica dos problemas jurídicos ultrapassa a simples pesquisa da legislação vigente e dos conceitos jurídicos abstratos apartados da realidade fático-social para construir um processo de transformação da mencionada realidade, chamada por Boaventura Santos de transição paradigmática (SANTOS, 2000, p. 257; WOLKMER, 2001 , p. 13), vincada na principiologia constitucional que irradia comandos peremptórios para as estruturas jurídicas (BARROSO, 2005, p. 236-242), a fim de minorar as desigualdades sociais (LÔBO, 2005, p. 108).

Isso rompe a arquitetura jurídica tradicional, diante da perspectiva renovada de uma leitura do Direito estribada na perspectiva constitucional e pós-positivista devendo o intérprete trabalhar com as três dimensões da constitucionalização (formal, material e prospectiva), como aponta Luiz Edson Fachin (2009, p. 9-15 e 12-13):

"É possível encetar pela dimensão formal, como se explica. A Constituição Federal brasileira de 1988 ao ser apreendida tão só em tal horizonte se reduz ao texto positivado, sem embargo do relevo, por certo, do qual se reveste o discurso jurídico normativo positivado. É degrau primeiro, elementar regramento proeminente, necessário, mas insuficiente.

Sobreleva ponderar, então, a estatura substancial que se encontra acima das normas positivadas, bem assim dos princípios expressos que podem, eventualmente, atuar como regras para além de serem mandados de otimização. Complementa e suplementa o norte formal anteriormente referido, indo adiante até a aptidão de inserir no sentido da constitucionalização os princípios implícitos e aqueles decorrentes de princípios ou regras constitucionais expressas. São esses dois primeiros patamares, entre si conjugados, o âmbito compreensivo da percepção intrassistemática do ordenamento.

Não obstante, o desafio é apreender extrassistematicamente o sentido de possibilidade da constitucionalização como ação permanente, viabilizada na força criativa dos fatos sociais que se projetam para o Direito, na doutrina, na legislação e na jurisprudência, por meio da qual os significados se constroem e refundam de modo incessante, sem juízos apriorísticos de exclusão. Nessa toada, emerge o mais relevante desses horizontes que é a dimensão prospectiva dessa travessia. O compromisso se firma com essa constante travessia que capta os sentidos histórico-culturais dos códigos e reescreve, por intermédio da ressignificação dessas balizas linguísticas, os limites e as possibilidades emancipatórias do próprio Direito".

A repersonalização (CARVALHO, 1985, p. 92) (análise do sujeito de direito nas suas relações concretas) das relações contratuais se reporta à imprescindível tarefa do 
jurista de hoje em se debruçar sobre as reflexões que o direito civil e o administrativo estão adstritos, para que seja realizado como fator de transformação social e de conformação dos interesses na luta por espaço de desenvolvimento econômico, social e ambiental.

A interpretação constitucional prospectiva dos institutos confere nova importância às instituiç̃os políticas; refunda o Estado em face da globalização; revitaliza a sociedade civil; democratiza as forças políticas por meio de mecanismos eleitorais incisivos e transparentes; redimensiona os meios de produção com a criação de instrumentos constitucionais para melhorar a distribuição de rendas; não recepciona institutos jurídicos estrangeiros inadequados à realidade estatal; modifica os objetivos da Administração Pública atrelados pela normatividade do Estado Democrático de Direito (SOARES In: ALMEIDA FILHO, PINTO FILHO, 2006, p. 48-67).

Os contratos civis são permeados por princípios individuais (relatividade objetiva, autonomia privada e força obrigatória dos contratos) e por princípios sociais (função social, função ambiental, boa-fé e equivalência material) - princípios supracontratuais que incidem em qualquer tipo de contrato, inclusive os administrativos, em razão do diálogo entre as formas de expressão do Direito.

Nessa ambiência, é possível haver diálogo entre as normas jurídicas civis e as normas incidentes sobre os contratos administrativos? As reflexões desenvolvidas no presente artigo indicam ser a positiva a resposta ao questionamento feito, principalmente se considerarmos as teses pós-positivistas aventadas nos tópicos anteriores, sendo possível derrotar dogmas e mitos dos direitos civil e administrativo, em homenagem à decisão justa para cada caso concreto.

O limite do diálogo (MARQUES, BENJAMIN e MIRAGEM, 2004, p. 25-52) é a incompatibilidade total de uma disciplina com a outra, pois, fora isso, são possíveis três tipos de comunicabilidade de formas de expressão do Direito:

(i) diálogo sistemático de coerência: constitui-se uma lei que serve de base conceitual para outra, como por exemplo, o conceito de nulidade, pessoa jurídica, prescrição e decadência; não estão nas normas de direito administrativo, mas no CC/02;

(ii) diálogo sistemático de complementariedade e subsidiariedade em antinomias aparentes ou reais: ocorre com a aplicação complementar ou subsidiária das leis e dos princípios, no que for necessário, como no de caso cláusulas gerais de uma lei incidirem em hipótese regulada por outra lei, a saber, arts. 721, 729, 732 e 777 do CC/02 e art. $7^{\circ}$ do CDC;

(iii) diálogo de influências recíprocas sistemáticas: apresenta uma inter-relação da norma geral com a especial e vice-versa, como nas hipóteses de aplicação do princípio da boa-fé, da função social e da equivalência material e do enfrentamento das cláusulas abusivas.

É irrefutável, destarte, o diálogo entre o direito civil e o direito administrativo não apenas no que aduz à principiologia, a enfraquecer a distinção entre contratos civis e 
administrativos, desde que a comunicabilidade seja possível, a derrotar o entendimento posto no acórdão objeto de apreciação.

A par disso, o contrato é um instrumento para a realização de um programa econômico, com o qual uma das partes concorda ou a ele adere, submetendo-se tanto às condições gerais do negócio, como aos seus riscos, vantagens, custos e benefícios atinentes à relação obrigacional pactuada, sempre observado e conformado aos princípios sociais do contrato. Ambas as partes cooperam para o adimplemento do pacto obrigacional. Avaliam-se, assim, os interesses de um negociante de acordo com a intenção/ conduta do outro.

Como visto, o acórdão escolhido não considerou o diálogo existente entre a principiologia contratual civil e a administrativa, como também procurou simplesmente aplicar o direito administrativo posto ao mesmo tempo em que afirmou não ser possível a incidência da principiologia trazida no art. $37 \mathrm{da} C F / 88$, porque a relação travada entre as partes não continha ente da Administração Pública direta ou indireta, a configurar um flagrante comportamento contraditório.

As reflexões em torno dos questionamentos abordados neste estudo pretendem contribuir para a adequada interpretação das formas de expressão do Direito no bojo das relações contratuais administrativas e civis, a fim de gerarem soluções efetivas e equânimes, que garantam o acesso processual e material à ordem jurídica, sendo certo que a teoria da derrotabilidade das normas jurídicas muito contribuirá para a efetivação real dos direitos das partes e de terceiros sintetizados em uma relação contratual de qualquer espécie.

\section{REFERÊNCIAS}

AGAMBEN, Giorgio. Estado de exceção. Trad. Iraci Poleti. São Paulo: Boitempo, 2004.

AMARAL, Francisco. Direito civil - introdução. 7. ed. Rio de Janeiro: Renovar, 2008.

AMARAL, Francisco. O Código Civil brasileiro e o problema metodológico de sua realização. In: TARTUCE, Flávio; CASTILHO, Ricardo (Coords.). Direito Civil. Estudos em Homenagem à Professora Giselda Maria Fernandes Novaes Hironaka. São Paulo: Método, 2006, p. 3-24.

AMARAL, Francisco. A interpretação jurídica segundo o Código Civil. Revista Brasileira de Direito Comparado, n. 29, p. 19-41, 2. ${ }^{\circ}$ sem. 2005.

ASSAGRA DE ALMEIDA, Gregório. Direito material coletivo: superação da summa divisio direito público e direito privado por uma nova summa divisio constitucionalizada. Belo Horizonte: Del Rey, 2008.

BARACHO, José Alfredo de Oliveira Teoria geral da cidadania. São Paulo: Saraiva, 1995.

BARROSO, Lucas Abreu. O prazo da usucapião extraordinária de servidão aparente. In: TARTUCE, Flávio; CASTILHO, Ricardo (Orgs.). Direito civil: direito patrimonial e direito existencial - estudos em homenagem à prof. ${ }^{a}$ Giselda Maria Fernandes Novaes Hironaka. São Paulo: Método, 2006, p. 601-610. 
BARROSO, Lucas Abreu. Situação atual do art. $4 .^{\circ}$ da Lei de Introdução ao Código Civiel. Revista Brasileira de Direito Constitucional, São Paulo, n. 5, p. 236-242, 2005.

BARROSO, Lucas Abreu; SOARES, Mário Lúcio Quintão. A dimensão dialética do novo Código Civil em uma perspectiva principiológica. In: BARROSO, Lucas Abreu (Org.). Introdução crítica ao Código Civil. Rio de Janeiro: Forense, 2006, p. 1-14.

BAYÓN, Juan Carlos. RODRÍGUEZ, Jorge. Relevancia normativa en la justificación de las decisiones judiciales: el debate Bayón-Rodriguez sobre la derrotabilidad de las normas jurídicas. Universidad Externado de Colombia, 2003.

BINENBOJM, Gustavo. A Constitucionalização do Direito Administrativo no Brasil: Um Inventário de Avanços e Retrocessos. In: NETO, Cláudio Pereira de Souza; SARMENTO, Daniel (Coords.). A Constitucionalização do Direito. Rio de Janeiro: Lumen Juris, 2007, p. 743-780.

BRANDOM, Robert. La articulación de las rezones. Madrid: Siglo Veintiuno de España Editores, 2002.

CANOTILHO, José Joaquim Gomes. Estado de direito. Lisboa: Gradiva, 1999.

CANOTILHO, JJ. Gomes. Jurisdição constitucional e novas intranquilidades discursivas: do melhor método a melhor teoria. In: Fundamentos: cuadernos monográficos de teoria del Estado, Derecho Publico e Historia Constitucional. n. 4, Oviedo: 2006, p. 427-439.

CARVALHO, Orlando de. Para uma teoria da relação jurídica civil: a teoria geral da relação jurídica: seu sentido e limites. 2. ed. Coimbra: Centelha, 1981.

COELHO, Luiz Fernando. Teoria crítica do direito. 3. ed. Belo Horizonte: Del Rey, 2003.

COELHO, Nuno Manuel Morgadinho dos Santos. DIREITO COMO PENSAMENTO EM A. CASTANHEIRA NEVES: O Jurisprudencialismo e o princípio da historicidade radical do direito. In: DIZ, Jamile Bergamaschine Mata; BARBOSA, Renata Almeida; ARANTES, Bruno Camilloto (Orgs.). Hermenêutica Jurídica: Uma análise contemporânea da interpretação e aplicação do Direito. Rio de Janeiro: Clássico Editora, 2008, p. 16-38.

ESPÍNDOLA, Ruy Samuel. Princípios constitucionais e atividade jurídico-administrativa: anotações em torno de questões contemporâneas. In: LEITE, George Salomão (Org.). Dos princípios constitucionais - considerações em torno das normas principiológicas da Constituição. São Paulo: Malheiros, 2003, p. 254-293.

FACHIN, Luiz Edson. Apresentação. In: CORTIANO JÚNIOR, Eroulths; MEIRELLES, Jussara Maria Leal de; FACHIN, Luiz Edson; NALIN, Paulo (Coords.). Apontamentos críticos para o direito civil brasileiro contemporâneo: anais do projeto de pesquisa virada de copérnico. Curitiba: Juruá, 2009, p. 9-15.

FACHIN, Luiz Edson. Aspectos do legado de Marx e para a teoria crítica do direito civil contemporâneo: uma releitura à luz da sagrada família. In: LIMA, Martônio Mont' Alverde Barreto; BELLO, Enzo (Coords.). Direito e marxismo. Rio de Janeiro: Lumen Juris, 2010, p. 143-154.

FACHIN, Luiz Edson. Teoria crítica do direito civil. 2. ed. Rio de Janeiro: Renovar, 2003.

FOUCAULT, Michel. Microfísica do poder. 11. reimpr. Rio de Janeiro: NAU, 1996.

FROTA, Pablo Malheiros da Cunha. Os deveres contratuais gerais nas relações civis e de consumo. Curitiba: Juruá, 2010, no prelo. 
FROTA, Pablo Malheiros da Cunha. A aplicabilidade da exceptio non adimpleti contractus aos contratos administrativos. In: HIRONAKA, Giselda Maria Fernandes Novaes; TARTUCE, Flávio. Direito contratual: temas atuais. São Paulo: Método, 2007, p. 547-580.

HABERMAS, Jurgen. Facticidad y validez. 3. ed. Madrid: Trotta, 2001.

HACK, Susan. Filosofia das lógicas. Trad. Cezar Augusto Mortari e Luiz Henrique de Araújo Dutra. São Paulo: Editora UNESP, 2002.

JUSTEN FILHO, Marçal. Curso de direito administrativo. 4. ed. São Paulo: Saraiva, 2009.

LIMONGI FRANÇA, Rubens. Instituições de direito civil. São Paulo: Saraiva, 1988.

LÔBO, Paulo Luiz Netto. Teoria geral das obrigações. São Paulo: Saraiva, 2005.

LÔBO, Paulo Luiz Netto. Transformações gerais do contrato. Revista Trimestral de Direito Civil, Rio de Janeiro: Padma, v. 16, p. 103-113, out.-dez. 2003.

LÔBO, Paulo Luiz Netto. Direito Civil. Parte Geral. São Paulo: Saraiva, 2009.

MACCORMICK, Neil. Retórica e o Estado de Direito. Trad. Conrado Hubner Mendes e Marcos Paulo Verissimo Rio de Janeiro: Campus, 2008.

MARQUES, Cláudia Lima; BENJAMIN, Antônio Herman V.; MIRAGEM, Bruno. Comentários ao Código de Defesa do Consumidor. São Paulo: RT, 2004.

NETO, Menelick de Carvalho. Os direitos fundamentais e a crise institucional do Distrito Federal. Palestra proferida na Faculdade Processus do Distrito Federal em 22 de fevereiro de 2010.

NEVES, A. Castanheira. O actual problema metodológico da interpretação jurídica. Coimbra: Ed. Coimbra, 2003, v. 1.

NEVES, A. Castanheira. A crise actual da filosofia do direito no contexto da crise global da filosofia. Coimbra: Coimbra Editora, 2003, (Stvdia Ivridica 72).

PERLINGIERI, Pietro. O direito civil na legalidade constitucional. trad. Maria Cristina de Cicco. Rio de Janeiro: Renovar, 2008.

PERLINGIERI, Pietro. Perfis do direito civil: introdução ao direito civil-constitucional. 2. ed. Rio de Janeiro: Renovar, 2002.

PETEFFI DA SILVA, Rafael. Sistema, códigos privados e a feudalização do direito. In: CAMBI, Eduardo; PEREIRA E SILVA, Reinaldo; LEWIS, Sandra A. Lopes B.; SANTOS, Sidney Francisco Reis dos; MARQUES, Siomara (Orgs.). Constituição, justiça e sociedade. Florianópolis: OAB/SC, 2006, v. 1, p. 137-174.

SANTOS, Boaventura de Sousa. A crítica da razão indolente: contra o desperdício da experiência. São Paulo: Cortez, 2000.

SERBENA, Cesar Antonio; CELLA, José Renato Gaziero. Prefácio. VASCONCELOS, Fernando Andreoni. Hermenêutica jurídica e derrotabilidade. Curitiba: Juruá, 2010.

SOARES, Mário Lúcio Quintão. Teoria do estado: novos paradigmas em face da globalização. 3. ed. São Paulo: Atlas, 2008.

SOARES, Mario Lucio Quintão. Constitucionalismo e Estado. In: ALMEIDA FILHO, Agassiz; PINTO FILHO, Francisco Bilac Moreira (Coords.). Constitucionalismo e Estado. Rio de Janeiro: Forense, 2006, p. 48-67. 
TARTUCE, Flávio; SIMÃO, José Fernando. Direito civil: direito de família. 2. ed. São Paulo: Método, 2007, v. 5.

TEPEDINO, Gustavo; BARBOZA, Heloísa Helena; MORAES, Maria Celina Bodin de (Orgs.). Código civil interpretado conforme a Constituição da república. 2. ed. Rio de Janeiro: Renovar, 2007, v. 1.

VASCONCELOS, Fernando Andreoni. Hermenêutica jurídica e derrotabilidade. Curitiba: Juruá, 2010.

WARAT, Luis Alberto. O direito e sua linguagem. 2. ed. Porto Alegre: Sérgio Antonio Fabris Editor, 1995.

WOLKMER, Antônio Carlos. Introdução ao pensamento jurídico crítico. 3. ed. São Paulo: Saraiva, 2001.

Recebido: agosto 2010

Aprovado: fevereiro 2011 
